\title{
Correction to: Evaluation of Orientation Dependence of Fracture Toughness and Fatigue Crack Propagation Behavior of As-Deposited ARCAM EBM Ti-6Al-4V
}

\author{
MOHSEN SEIFI,${ }^{1,4}$ MATTHEW DAHAR, ${ }^{1}$ RON AMAN ${ }^{2}$ \\ OLA HARRYSSON, ${ }^{2}$ JACK BEUTH, ${ }^{3}$ and JOHN J. LEWANDOWSKI ${ }^{1,5}$ \\ 1.-Department of Materials Science and Engineering, Case Western Reserve University, Clev- \\ eland, OH, USA. 2.-Department of Industrial and Systems Engineering, North Carolina State \\ University, Raleigh, NC, USA. 3.-Department of Mechanical Engineering, Carnegie Mellon \\ University, Pittsburgh, PA, USA. 4.—e-mail: mohsen.seifi@case.edu. 5.—e-mail: jjl3@case.edu
}

\section{Correction to:}

JOM (2015) 67(3)

doi https://doi.org/10.1007/s11837-015-1298-7

There was a typographical error in Fig. $2 b$ in the original publication of this article. It has been corrected in the image below.

(b)

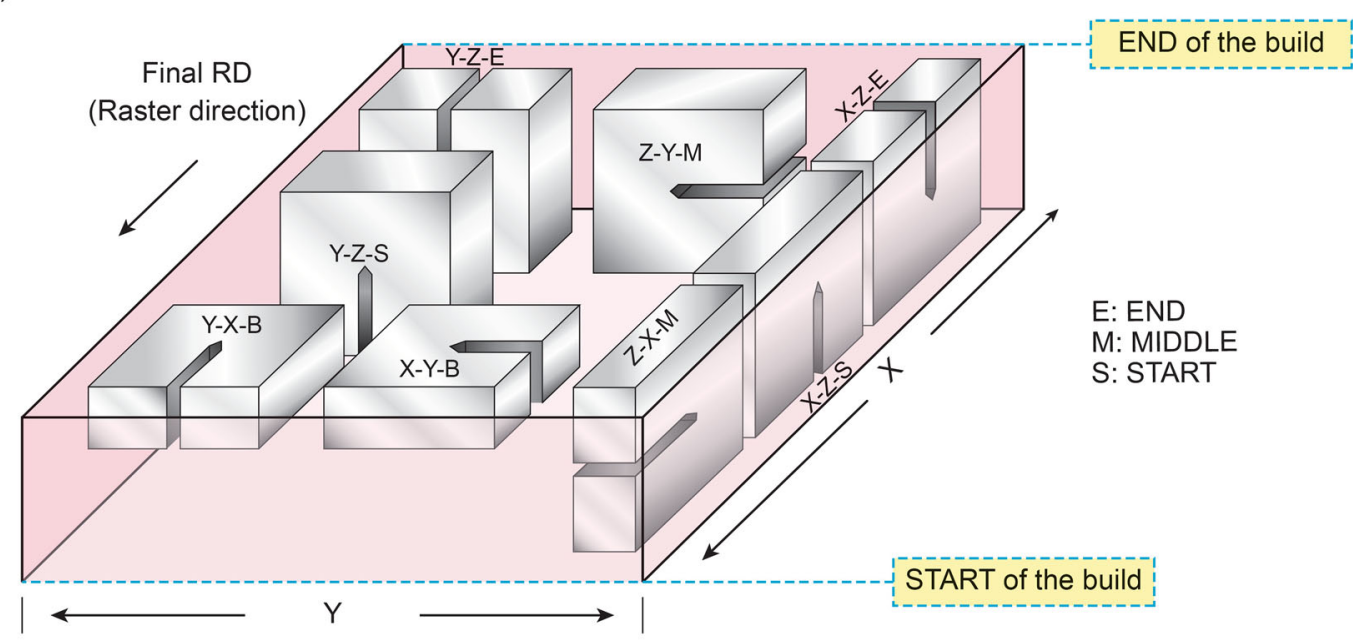

Possible designations for AM parts based on ISO standard

Z, Build Direction

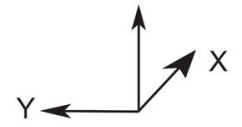

8 Different orientation/direction combinations

The online version of the original article can be found under doi https://doi. org/10.1007/s11837-015-1298-7. 